\title{
Pathways to urban health and well-being: measuring and modelling of community services in a medium size city
}

\author{
Clémence Vannier, ${ }^{1}$ Malcolm Campbell, ${ }^{2}$ Simon Kingham $^{2}$ \\ ${ }^{1}$ GeoHealth Laboratory, University of Canterbury, Christchurch, New Zealand \\ ${ }^{2}$ Department of Geography, University of Canterbury, Christchurch, New Zealand
}

\begin{abstract}
Social and natural capital are fundamental to people's wellbeing, often within the context of local community. Developing communities and linking people together provide benefits in terms of mental well-being, physical activity and other associated health outcomes. The research presented here was carried out in Christchurch - Ōtautahi, New Zealand, a city currently re-building, after a series of devastating earthquakes in 2010 and 2011. Poor mental health has been shown to be a significant post-earthquake problem, and social connection has been postulated as part of a solution. By curating a disparate set of community services, activities and facilities, organised into a Geographic Information Systems (GIS) database, we created i) an accessibility analysis of 11 health and well-being services, ii) a mobility scenario analysis focusing on 4 general well-being services and iii) a location-allocation model focusing on 3 primary health care and welfare loca-
\end{abstract}

Correspondence: Clémence Vannier, 1GeoHealth Laboratory, University of Canterbury, Christchurch, New Zealand

E-mail: vannier.clemence@gmail.com

Key words: Community facilities; accessibility; Health and Well-being; location/allocation modelling; medium size city.

Funding: This research carried out on the WellConnectedNZ (https://www.wellconnectednz.org/) project funded by the Health Research Council of NZ and the Ministry of Health. WellConnectedNZ is a project within the Healthier Lives National Science Challenge, one of 11 National Science Challenges designed to find solutions to large, complex issues facing NZers. This research was hosted at the University of Canterbury, Geography department, and the GeoHealth Laboratory of the College of Science.

Conflict of Interest: The Authors declare no potential conflict of interests.

Received for publication: 23 August 2019.

Accepted for publication: 27 Febrtuary 2020.

(C) Copyright: the Author(s), 2020

Licensee PAGEPress, Italy

Geospatial Health 2020; 15:808

doi:10.4081/gh.2020.808

This article is distributed under the terms of the Creative Commons Attribution Noncommercial License (CC BY-NC 4.0) which permits any noncommercial use, distribution, and reproduction in any medium, provided the original author(s) and source are credited. tion optimisation. Our results demonstrate that overall, the majority of neighbourhoods in Christchurch benefit from a high level of accessibility to almost all the services; but with an urban-rural gradient (the further away from the centre, the less services are available, as is expected). The noticeable exception to this trend, is that the more deprived eastern suburbs have poorer accessibility, suggesting social inequity in accessibility. The findings presented here show the potential of optimisation modelling and database curation for urban and community facility planning purposes.

\section{Introduction}

'Community wellbeing is the combination of social, economic, environmental, cultural, and political conditions identified by individuals and their communities as essential for them to flourish and fulfil their potential.' (Wiseman and Brasher, 2008).

Social and natural capital have been shown to be fundamental to human well-being (Costanza et al., 1997; Nahapiet and Ghoshal, 1998; Wiseman and Brasher, 2008; Guerry et al., 2015). An important part of personal social capital is an individual's community, which can be families, small groups of people or larger communities, and it has been shown to support physical health and well-being (Helliwell and Putnam, 2004; Vemuri and Costanza, 2006). In Māori culture in New Zealand - Aotearoa (NZ), communities have a central place in the organisation of society. Symbolically, communities can be viewed as being held together in a basket (kete) with the basket of health (Te Kete Hauora) as ultimate goal. In order for the kete to be strong it needs many strands of flax (harakeke) to come together and be woven tight. Those strands represent the many people, cultures and ethnicities that make up NZ. The strength of the kete affects the health and well-being condition of the community (Cram et al., 2006; Harmthworth and Awatere, 2013; Sargisson et al., 2017). These cultural symbols and the central place given to community in NZ society reflect Māori culture, which places a high values on community (Grant, 2017). A strong community needs strong social relations between people in communities, and is a key ingredient of both individual and community well-being (Costanza et al., 2007; Bagnall et al., 2018). Generally, linking people together and re-establishing the concept of a 'city of villages' has been shown to have benefits in terms of well-being, physical activity, and health (Albino et al., 2015; Marans, 2015; Sargisson et al., 2017). In a rebuilding-city context following a post-disaster environment, Christchurch - Ōtautahi, a medium size city in NZ, provided the opportunity to explore different 
futures, to be innovative and improve the quality of life of its residents as it rebuilt. The 2010/2011 earthquake sequence resulted in $80 \%$ of the city centre being demolished due to major structural damage and is still in rebuilding process which will continue well past 2020 (Wood et al., 2016). Christchurch lost a lot of its infrastructure which impacted city life in many ways, with the social impact still ongoing and the long-term cost difficult to estimate (Hogg et al, 2016; Orchiston and Higham, 2016). Since 2011, a number of planning decisions, with consultation and collaboration between stakeholders, researchers, communities and local governments, have taken place to help produce the best reconstruction options (Kingham et al., 2015). The city has started to return to a more normal, less disrupted state, although it remains in a planning and rebuilding process (Marek et al., 2017). It is essential then to provide an overview of the basic primary health care and wellbeing services supplied to the Christchurch residents and their potential accessibility.

Accessibility can be defined as the ease of reaching destinations and geographical accessibility as the travel impedance between people and a given location (Neutens, 2015). The use of Geographic Information Systems (GIS) to compute geographical accessibility (hereafter just named accessibility) has proven to be an effective and efficient approach (Wiki et al., 2018; McGrail and Humphreys, 2014; Pearce et al., 2006; Bagheri, Benwell, Holt, 2005). Where much work has been done measuring accessibility using GIS (Neutens, 2015), it is still important because of its ongoing importance in land use planning. For example, many GIS accessibility studies are still carried out looking at transportation improvement or service location to public parks (Meng and Malczewski, 2015), urban green spaces (Cetin, 2015), cultural ecosystem services (Ala-Hulkko et al., 2016) and to primary health care services (Bagheri et al., 2005; McGrail and Humphreys, 2014), and the links between green spaces and human health (Ekkel and de Vries, 2017) have been analysed this way. Likewise, GIS accessibility analysis, such as location-allocation models (L/As) are also frequently used to improve spatial planning of public health (Beheshtifar and Alimoahmmadi, 2015; Polo et al., 2015; Zhang et al., 2016). In NZ, the first accessibility analysis using GIS technology to measure community resource locations was done in 2006 (Pearce et al., 2006). This study found clear and expected spatial variation across the country including urban and rural areas. More recently, an accessibility analysis based on GIS has found socio-spatial relationships between food retailers and socio-economic deprivation in urban NZ, highlighting important implications for policy initiatives, health outcomes and sustainable development (Wiki et al., 2018).

Accessibility analysis and optimisation models are widely used to help identify the optimum location of health services, but less frequently for access to local community facilities. However it has the potential to allow a better understanding of how local services can be used by, and within, a community (Wridt, 2010), as well as for the planning of community needs (Masser, 2001; Yeo et al., 2013). In this context, the aim of this paper is to measure and model community accessibility in Christchurch, NZ through the lens of a wide range of services that have been linked to positive health and well-being outcomes. For this purpose, this paper has three objectives: 1). to map and quantify current accessibility; 2). to analyse scenarios by different transport mode; and 3). to use a L/A model to identify locations to optimize accessibility to the primary health care and welfare services.

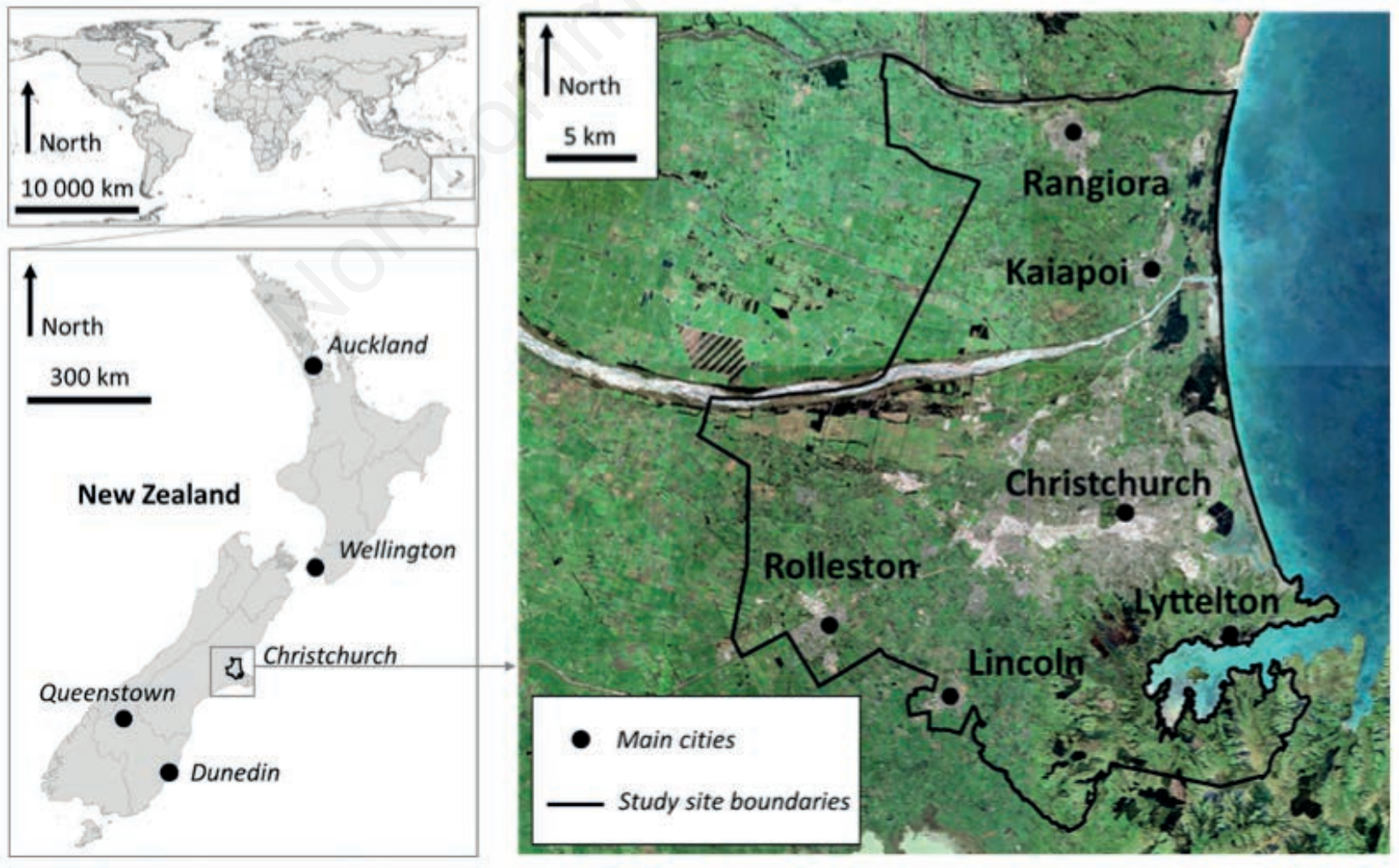

Figure 1. Christchurch - Ōtautahi catchment area. 


\section{Materials and Methods}

\section{Study site}

The study included the city of Christchurch and its greater urban catchment area (Figure 1) from Rangiora in the North to Rolleston and Lincoln in the South-west including the port of Lyttelton. Located on the coastal edge of the Canterbury plains, the study area extends $50 \mathrm{~km}$ from north to south and $35 \mathrm{~km}$ from east to west (approximately $1,200 \mathrm{~km}^{2}$ ) of a largely flat area with hills on the southern boundary. Christchurch is the major urban area in the South Island, the third largest urban area in NZ with 381,800 people in the urban area, and 401,961 people in the whole study area (according to 2013 census). Founded in 1856 as a Garden City, Christchurch is one of the oldest urban settlements in the country. The central city is configured in a regular grid and Christchurch's suburbs are characterised by low property and population densities with large property areas (Kingham et al., 2015).

\section{GIS Data}

Several types of spatial data were collected (Table 1) from: The Ministry of Health $(\mathrm{MoH})$ and Ministry for the Environment
(MfE) in NZ, Community Information Christchurch (CINCH), Open Street Map (OSM), Land Information New Zealand (LINZ), and Statistics New Zealand (STATSNZ). Data were acquired in a $20 \mathrm{~km}$ buffer around the Christchurch catchment area (as accessibility analysis does not assume that all the facilities are located inside the catchment area). The data was first projected to the 'NZGD 2000 NZ Transverse Mercator' and subsequently organised in a Geographic Information System (GIS) into four categories: i) People (source): point data of population weighted centroids (PWC) per meshblocks (i.e. the smallest geographic unit for which statistical data is collected and processed by STATNZ) $(\mathrm{n}=3,971$ meshblocks, population $=401,961)$ and population density in people $/ \mathrm{km}^{2}$ for each meshblock (see supplementary material S1). ii) Health and welfare (target): location of general practitioners (GPs), hospitals and medical centres, pharmacies, ambulances, and other health services $(\mathrm{n}=529)$, as well as welfare places (i.e. services designed to promote basic help to people in need) like parenting groups, groups for single mothers, older people and so on $(\mathrm{n}=109)$. iii) Socio-cultural places (target): location of community groups (worship, associations, society and clubs, lodges, trusts and trustees, other social groups, marae, etc., $\mathrm{n}=917$ ); cultural groups (art, dance, drama, music, heritage, museums, etc., $\mathrm{n}=535$ ); educa-

Table 1. GIS data sources.

\begin{tabular}{|c|c|c|c|c|c|c|}
\hline Category & & Description & Source & Date & Scale & Number \\
\hline People & Population & $\begin{array}{l}\text { - Population by Meshblock weighted centroids } \\
\text { - Population density }\end{array}$ & Statistics NZ & 2013 & National & $\begin{array}{c}3,971 \\
\text { (out of } 401,961 \text { ) }\end{array}$ \\
\hline Health and Welfare & Health & $\begin{array}{l}\text { - General practitioners } \\
\text { - Hospitals and medical centres } \\
\text { - Pharmacies } \\
\text { - Ambulances } \\
\text { - Other health services (specialists) } \\
\text { - Parenting, single mothers, older people, etc. }\end{array}$ & $\begin{array}{l}\text { MoH, } \\
\text { OSM } \\
\text { CINCH }\end{array}$ & $\begin{array}{l}2017 \\
2018 \\
2018\end{array}$ & $\begin{array}{l}\text { National } \\
\text { National } \\
\text { Local }\end{array}$ & 529 \\
\hline \multirow[t]{5}{*}{ Socio-Cultural } & Community & $\begin{array}{l}\text { - Worship and ethnic groups } \\
\text { - } \quad \text { Lodges, associations, etc. } \\
\text { - } \quad \text { Society and clubs (youth, women, etc.) } \\
\text { - Trusts and trustees } \\
\text { - Other social groups } \\
\text { - Marae }\end{array}$ & $\begin{array}{l}\text { OSM } \\
\text { LINZ } \\
\text { CINCH }\end{array}$ & $\begin{array}{l}2018 \\
2018 \\
2018\end{array}$ & $\begin{array}{l}\text { National } \\
\text { National } \\
\text { Local }\end{array}$ & 917 \\
\hline & Cultural & $\begin{array}{l}\text { - Art, dance, drama, music, etc. } \\
\text { - Heritage and attraction sites } \\
\text { - Museums }\end{array}$ & $\begin{array}{l}\text { OSM } \\
\text { CINCH }\end{array}$ & $\begin{array}{l}2018 \\
2018\end{array}$ & $\begin{array}{l}\text { National } \\
\text { Local }\end{array}$ & 535 \\
\hline & Education & $\begin{array}{l}\text { - Preschools, kindergarten, etc. } \\
\text { - Schools and high-schools } \\
\text { - University } \\
\text { - Other education places }\end{array}$ & $\begin{array}{l}\text { OSM } \\
\text { CINCH }\end{array}$ & $\begin{array}{l}2018 \\
2018\end{array}$ & $\begin{array}{l}\text { National } \\
\text { Local }\end{array}$ & 792 \\
\hline & Sport and Recreation & $\begin{array}{l}\text { - Athletic, rugby, fitness, martial art, etc. } \\
\text { - Golf courses, parks, playgrounds, etc. }\end{array}$ & $\begin{array}{l}\text { OSM } \\
\text { LINZ } \\
\text { CINCH }\end{array}$ & $\begin{array}{l}2018 \\
2018 \\
2018\end{array}$ & $\begin{array}{l}\text { National } \\
\text { National } \\
\text { Local }\end{array}$ & 1,198 \\
\hline & Food and drink & $\begin{array}{l}\text { - Restaurants, supermarkets, fast food, etc. } \\
\text { - Café, bar, etc. }\end{array}$ & OSM & 2018 & National & 711 \\
\hline \multirow[t]{2}{*}{ Green and blue spaces } & Green spaces & $\begin{array}{l}\text { - Grasslands } \\
\text { - Forests (natural or planted) } \\
\text { - Native vs exotic vegetation } \\
\text { - Scrubs } \\
\text { - Shelterbelts } \\
\text { - Orchards and vineyards }\end{array}$ & $\begin{array}{l}\text { MfE } \\
\text { LINZ }\end{array}$ & $\begin{array}{l}2018 \\
2018\end{array}$ & $\begin{array}{l}\text { National } \\
\text { National }\end{array}$ & 24,555 \\
\hline & Blue spaces & $\begin{array}{l}\text { - Lakes } \\
\text { - Wetlands (swamp, mud, pond) } \\
\text { - River } \\
\text { - Sand }\end{array}$ & $\begin{array}{l}\text { MfE } \\
\text { LINZ }\end{array}$ & $\begin{array}{l}2018 \\
2018\end{array}$ & $\begin{array}{l}\text { National } \\
\text { National }\end{array}$ & 6,691 \\
\hline
\end{tabular}

Meshblock is the smallest geographic unit for which statistical data is collected and processed by STATNZ. MoH = Ministry of Health, MfE = Ministry for the Environment https:/data.mfe.govt.nz/, CINCH = Community INformation Christchurch http://www.cinch.org.nz/, OSM = Open Street Map http://download.geofabrik.de/australia-oceania/new-zealand.html, LINZ = Land Information NZ https://data.linz.govt.nz/, Statistics NZ https:/datafinder.stats.govt.nz/. 
tion places (preschools, kindergarten schools, colleges, highschools, university, etc., $\mathrm{n}=792$ ); and sport and recreation places $(n=1,198)$, such as food and drink facilities (restaurants, supermarkets, fast-food, café, bar, etc., $(\mathrm{n}=711)$. iv) Green and blue spaces (target): represented all the green and blue areas in the study site (grassland, forest, exotic or native vegetation, scrub, lakes, wetlands, rivers, etc.) The population numbers were for green spaces: $n=24,555$, and for blue spaces: $n=6,691$ ). To compute accessibility analysis, a road network data was used (Beere, 2016).

\section{GIS analysis}

Three types of GIS processing were computed: an accessibility analysis of all services $(n=11)$; a scenario analysis focusing on four general well-being services; and a L/A modelling focusing on three primary health care and welfare services. All the GIS analyses were computed using ArcGIS 10.4.1. software (ESRI Redlands, CA, USA).

\section{Accessibility analysis}

In the GIS analysis, accessibility was defined as travel time or distance, between demand (e.g., people) and supply (e.g., a service). In other words, accessibility was calculated here as a geographical measure between where people live and where the nearest type of facility is located. The measured accessibility represented the availability of a given service in a given neighbourhood. It did not measure the realised accessibility which refers to other socio-economic factors than only geographical measurements.

The accessibility analysis was computed to determine the required travel time and distance for people to reach a specific location. The travel time/distance was performed between (i) the place of residence (i.e. demand - determined by meshblock weighted centroids) and (ii) the service locations (i.e. supply - facility places determined by socio-environmental data). The objective was to determine the distance and time required for people to access their closest service for each category.

Travel distance (i.e. walking distance) analysis was computed for Euclidian distance in metres between the place of residence and the closest facility of a given type of service (i.e. health, welfare, community, cultural, education, sport and recreation, food and drink, green and blue spaces). Travel time was based on min driving by car. Travel time estimates per services were calculated based on road network data (Beere, 2016). Travel time and distance estimates were computed separately for the following categories: all health and welfare, GPs, public hospitals, pharmacies, welfare, community, cultural, education, sport and recreation, food and drink, green spaces, blue spaces.

\section{Scenario analysis}

The objective of the scenarios was to determine the number of people covered by the current service facilities within a reasonable travel distance or time. We combined the accessibility maps (travel distance and travel time separately) within two scenarios, walking or driving, to four well-being services: health and welfare, community places, cultural places, sport and recreation activities. The two scenarios were:

- Walking Scenario, which was calculate as the walking distance (in metres) between the place of residence and the chosen ser- vice category. Walking speed was estimated at around $4.5 \mathrm{~km} / \mathrm{h}$ (Chen et al., 1997; Terrier and Reynard, 2015). The chosen thresholds were i) less than 10 min walking for a good level of accessibility (i.e. less than $750 \mathrm{~m}$ that represented a reasonable walking threshold; Smoyer-Tomic et al., 2004), ii) between 10 to 20 min walking for a medium level of accessibility (between 750 to $1,500 \mathrm{~m}$ ), iii) more than 20 min walking was considered as a low level of accessibility (>1,500 metres; Tsou et al., 2005); and

- Driving Scenario, which was calculated as the driving time (in min) between place of residence and the chosen service category. The estimated driving speed was the maximum speed limit, varying according to road configurations (Beere, 2016). The chosen thresholds were i) $<5$ min driving for a good level of accessibility, ii) 5-10 min driving for a medium level of accessibility, iii) $>10$ min driving for a low level of accessibility for a medium size city in the NZ context (Langford and Higgs, 2006; Pearce et al., 2006; Neutens, 2015).

A synthesis analysis was computed for the two scenarios. The objective was to map the areas with high, medium or low levels of accessibility for all services. Firstly, we mapped separately the accessibility level for the four selected services and for the two scenarios using the time and distance maps and following the scenario thresholds. Secondly, we merged together the four service maps for each scenario to produce a synthetic map of accessibility level to all services for the Christchurch study area.

\section{A location-allocation model}

A L/A model was computed to create scenarios that increase accessibility to primary health care and welfare services. The objective of the model was to determine the optimal location of a given service according to a given demand. This type of model allows to optimize travel distance or time between people (demand) and services (facility locations), but it does not take into account the number of people that are likely to receive by an existing facility. Consequently, the optimal number could not provide sufficient service for the whole population.

The objective of this model was to define, given demand, where would be the best facility locations in order to increase accessibility. The two scenarios (walking and driving) were tested in this model. Most of the L/A models in the literature defined $<10$ min driving as an acceptable driving time to reach a facility (Langford and Higgs, 2006; Pearce et al., 2006). Therefore, we kept this threshold to compute the driving scenario. Under the driving scenario, we analysed how the changes required would affect pedestrians.

The L/A model we developed was based on: i) Demand: people place of residence (determined by meshblock weighted centroids); ii) Services: all the health and welfare existing services as a bundle of available places for primary health care service locations; and iii) Transport: car driving using a GIS road network according to Beere (2016).

The model was computed for three different services (GPs, pharmacies, welfare places) and following three different scenarios: i) minimizing the number of facilities; ii) maximizing the attendance and so increase the current accessibility; and iii) maximizing the coverage of a given type of service. 


\section{Results}

\section{Accessibility analysis}

The accessibility analysis allowed computation and mapping of the travel time and distance from a place of residence to the closest service facility. Summary statistics are presented (Table 2). Figures 2 and 3 display travel distance and time accessibility maps presented in quintiles (referring to Table 2) for the 9 main services (Figures 2 and 3 exclude green and blue spaces presented in supplementary material S2). For the whole catchment area, the mean and median travel distances for most of the services (except public hospitals and welfare) were less than $1 \mathrm{~km}$ (Table 2). As there are only three public hospitals in the study area, the public hospital accessibility cannot be compared with other type of services. For health and welfare services, the GPs and pharmacies facilities are well distributed across the study area and the mean distance is just less than $1 \mathrm{~km}$, and the mean driving time is less than $2.5 \mathrm{~min}$ (Table 2). Welfare facilities are sparsely and unevenly spatially distributed. There are more than a hundred welfare facilities, but the mean distance between people and the nearest facility is more than $1.6 \mathrm{~km}$ (Table 2). The socio-cultural places are easily reachable with a mean distance around $500 \mathrm{~m}$, so they can be reached easily by walking, otherwise the mean driving time is very small, around 1 to $<2 \mathrm{~min}$ (Table 2). Green and blue spaces are well distributed and easily accessible too (means are $204 \mathrm{~m}$ and $441 \mathrm{~m}$, respectively (Table 2), which means that these places are spread all over the city (see supplementary material S2). This can be considered a good point given that these elements had proven to be as positive impact in mental health and well-being for the whole population regardless of age or condition (Finlay et al., 2015; Gascon et al., 2015; Thompson and Aspinall, 2011).

The different services seem to be well distributed spatially (Figures 2 and 3). Although Christchurch City is well covered by a wide range of services than peripheral areas, there is no evident city centre. Maps display a multi-centred city offering a well spread and wide range of facilities for all the type of services across a large number of neighbourhoods. This pattern is particularly evident in the travel distance maps (Figure 2). The travel driving-time pattern is slightly different (Figure 3 ). The accessibility is more clustered around the facilities especially for the medium to low accessibility classes. For population density (Supplementary material S1), the supply of services seemed to serve most areas well, with the exception of the eastern suburbs looking less well served (Figure 2).

\section{Scenario analysis}

The scenario objective was to determine the number of people covered by the current service facilities within a reasonable travel distance or time. As a reminder, the walking scenario defined an average speed of $4.5 \mathrm{~km} / \mathrm{h}$ with thresholds being less than $10 \mathrm{~min}$, $10-20 \mathrm{~min}$ and $>20 \mathrm{~min}$ corresponding to $<750 \mathrm{~m}, 750-1,500 \mathrm{~m}$, and $>1,500 \mathrm{~m}$. These selected thresholds generally match up globally to the second and fourth quintile of the travel distance analysis (Table 2). The driving scenario time thresholds used are $<5 \mathrm{~min}, 5$ $10 \mathrm{~min}$, and $>10 \mathrm{~min}$, which correspond to the same quintiles of the travel time analysis (Table 2).

The number and percentage of people covered by facilities within the chosen thresholds for the walking and driving scenarios

Table 2. Summary statistics of accessibility analysis.

\begin{tabular}{|c|c|c|c|c|c|c|c|c|c|}
\hline Category & Median & Mean & SD & Q1 & Q2 & Q3 & Q4 & Q5 & Maximum \\
\hline All health and welfare & $\begin{array}{c}416.9 \\
1.24\end{array}$ & $\begin{array}{c}647.4 \\
1.57\end{array}$ & $\begin{array}{c}840.3 \\
1.35\end{array}$ & $\begin{array}{c}4.4 \\
0\end{array}$ & $\begin{array}{l}207 \\
0.64\end{array}$ & $\begin{array}{l}341 \\
1.03\end{array}$ & $\begin{array}{r}508 \\
1.5\end{array}$ & $\begin{array}{c}789.5 \\
2.14\end{array}$ & $\begin{array}{c}8,231.5 \\
11.32\end{array}$ \\
\hline GPs & $\begin{array}{r}683.7 \\
1.88 \\
\end{array}$ & $\begin{array}{c}970.3 \\
2.28 \\
\end{array}$ & $\begin{array}{c}1,051.5 \\
1.72 \\
\end{array}$ & $\begin{array}{l}22.8 \\
0.02 \\
\end{array}$ & $\begin{array}{r}369.7 \\
1.07 \\
\end{array}$ & $\begin{array}{c}575.8 \\
1.6 \\
\end{array}$ & $\begin{array}{c}815.4 \\
2.17 \\
\end{array}$ & $\begin{array}{l}1270 \\
3.16 \\
\end{array}$ & $\begin{array}{c}12,331.5 \\
14.1\end{array}$ \\
\hline Public hospitals & $\begin{array}{c}3925.7 \\
8.8\end{array}$ & $\begin{array}{c}5,502.5 \\
9.9\end{array}$ & $\begin{array}{l}4980 \\
5.57\end{array}$ & $\begin{array}{l}64.2 \\
0.49\end{array}$ & $\begin{array}{c}1977 \\
5.8\end{array}$ & $\begin{array}{c}3339 \\
7.9\end{array}$ & $\begin{array}{l}4666 \\
9.74\end{array}$ & $\begin{array}{l}7235 \\
13.1\end{array}$ & $\begin{array}{c}26,463.4 \\
34.6\end{array}$ \\
\hline Pharmacies & $\begin{array}{c}690.1 \\
1.89\end{array}$ & $\begin{array}{c}994.4 \\
2.4\end{array}$ & $\begin{array}{c}1,092.6 \\
2.33\end{array}$ & $\begin{array}{c}9 \\
0.001\end{array}$ & $\begin{array}{c}385.3 \\
1.1\end{array}$ & $\begin{array}{c}584.3 \\
1.63\end{array}$ & $\begin{array}{c}803 \\
2.2\end{array}$ & $\begin{array}{l}1233 \\
3.15 \\
\end{array}$ & $\begin{array}{c}11,336.1 \\
34.55\end{array}$ \\
\hline Welfare & $\begin{array}{c}909.3 \\
2.45\end{array}$ & $\begin{array}{c}1,677.6 \\
3.5\end{array}$ & $\begin{array}{c}1,948.7 \\
3.5\end{array}$ & $\begin{array}{c}4.4 \\
0.001\end{array}$ & $\begin{array}{l}406 \\
1.22\end{array}$ & $\begin{array}{c}715.7 \\
1.98\end{array}$ & $\begin{array}{c}1,187.6 \\
3\end{array}$ & $\begin{array}{c}2452.8 \\
4.9\end{array}$ & $\begin{array}{c}11,881.4 \\
34.25\end{array}$ \\
\hline Community & $\begin{array}{c}337.1 \\
1.1\end{array}$ & $\begin{array}{c}540.5 \\
1.4\end{array}$ & $\begin{array}{c}770.4 \\
1.29\end{array}$ & $\begin{array}{c}3.3 \\
0\end{array}$ & $\begin{array}{c}165.3 \\
0.53\end{array}$ & $\begin{array}{l}278 \\
0.88\end{array}$ & $\begin{array}{c}410.3 \\
1.28\end{array}$ & $\begin{array}{l}657 \\
1.95 \\
\end{array}$ & $\begin{array}{l}9439 \\
13.18 \\
\end{array}$ \\
\hline Cultural & $\begin{array}{c}488.5 \\
1.44\end{array}$ & $\begin{array}{c}686.6 \\
1.76\end{array}$ & $\begin{array}{l}724 \\
1.38\end{array}$ & $\begin{array}{c}13.8 \\
0\end{array}$ & $\begin{array}{c}237.8 \\
0.73\end{array}$ & $\begin{array}{c}395.8 \\
1.2\end{array}$ & $\begin{array}{c}586.1 \\
1.7\end{array}$ & $\begin{array}{c}920.5 \\
2.5\end{array}$ & $\begin{array}{c}7,585.2 \\
11.44\end{array}$ \\
\hline Education & $\begin{array}{l}305 \\
0.9\end{array}$ & $\begin{array}{l}454.5 \\
1.22\end{array}$ & $\begin{array}{c}549.1 \\
1.02\end{array}$ & $\begin{array}{c}5.5 \\
0\end{array}$ & $\begin{array}{l}165 \\
0.51\end{array}$ & $\begin{array}{l}253 \\
0.81\end{array}$ & $\begin{array}{l}360 \\
1.15\end{array}$ & $\begin{array}{c}554.8 \\
1.7\end{array}$ & $\begin{array}{c}5,906.6 \\
9\end{array}$ \\
\hline Sport and recreation & $\begin{array}{c}316.8 \\
1\end{array}$ & $\begin{array}{c}422.9 \\
1.14\end{array}$ & $\begin{array}{c}432.3 \\
0.81\end{array}$ & $\begin{array}{c}3.3 \\
0\end{array}$ & $\begin{array}{c}169.2 \\
0.5\end{array}$ & $\begin{array}{c}262.4 \\
0.83\end{array}$ & $\begin{array}{c}377.4 \\
1.16\end{array}$ & $\begin{array}{c}553.5 \\
1.65\end{array}$ & $\begin{array}{c}4,787.1 \\
9.32\end{array}$ \\
\hline Food and drink & $\begin{array}{c}517.4 \\
1.42\end{array}$ & $\begin{array}{c}732.8 \\
1.85 \\
\end{array}$ & $\begin{array}{c}580.4 \\
1.6\end{array}$ & $\begin{array}{c}9.8 \\
0\end{array}$ & $\begin{array}{c}249.2 \\
0.74\end{array}$ & $\begin{array}{c}418.4 \\
1.18\end{array}$ & $\begin{array}{c}628.5 \\
1.7\end{array}$ & $\begin{array}{c}966.1 \\
2.6\end{array}$ & $\begin{array}{c}8,442.5 \\
15.85\end{array}$ \\
\hline Green spaces & $\begin{array}{r}168.7 \\
0.85\end{array}$ & $\begin{array}{c}203.9 \\
0.89\end{array}$ & $\begin{array}{c}166.1 \\
0.54\end{array}$ & $\begin{array}{l}0 \\
0\end{array}$ & $\begin{array}{c}73.1 \\
0.4\end{array}$ & $\begin{array}{c}134.5 \\
0.7\end{array}$ & $\begin{array}{c}206 \\
1\end{array}$ & $\begin{array}{c}312.2 \\
1.33\end{array}$ & $\begin{array}{c}1,586.6 \\
5.6\end{array}$ \\
\hline Blue spaces & $\begin{array}{l}355 \\
2.15\end{array}$ & $\begin{array}{l}441 \\
2.25\end{array}$ & $\begin{array}{c}347.1 \\
1.24\end{array}$ & $\begin{array}{l}0 \\
0\end{array}$ & $\begin{array}{c}145.1 \\
1.12\end{array}$ & $\begin{array}{l}274 \\
1.83\end{array}$ & $\begin{array}{c}441.9 \\
2.5\end{array}$ & $\begin{array}{c}695.3 \\
3.31\end{array}$ & $\begin{array}{c}2,320.8 \\
6.7\end{array}$ \\
\hline
\end{tabular}

$\mathrm{SD}=$ Standard deviation; Walking distance $(\mathrm{m})$; Travel time by car $(\mathrm{min})$. 
are presented in Table 3. The results confirm what was already shown by the accessibility analysis that the supply of services seems to serve most communities well. Almost $97 \%$ of the Christchurch catchment population are covered by a health or welfare facility within 5 min driving time (Table 3), with $94.6 \%$ and $98.7 \%$ of the population living less than 5 or 10 min driving time from the nearest GP, $93.4 \%$ and $98.3 \%$ living less than 5 or $10 \mathrm{~min}$ from the nearest pharmacy, and $80.1 \%$ and $94.5 \%$ living less than
5 or $10 \mathrm{~min}$ from the nearest welfare facility. The community, cultural, educational, sport, recreation, food and drink places are also really well distributed as $95 \%$ of the population are less than $5 \mathrm{~min}$ away if driving and more than $99 \%$ less than 10 min (Table 3).

These services are less accessible for people relying on walking, with $80 \%$ living $<10$ min walk from a health or welfare facility, and $92.4 \%<20 \mathrm{~min}$ (Table 3 ). Only $56.6 \%$ of people live less than a 10 min walk from their nearest GP, but it increases to $86.6 \%$

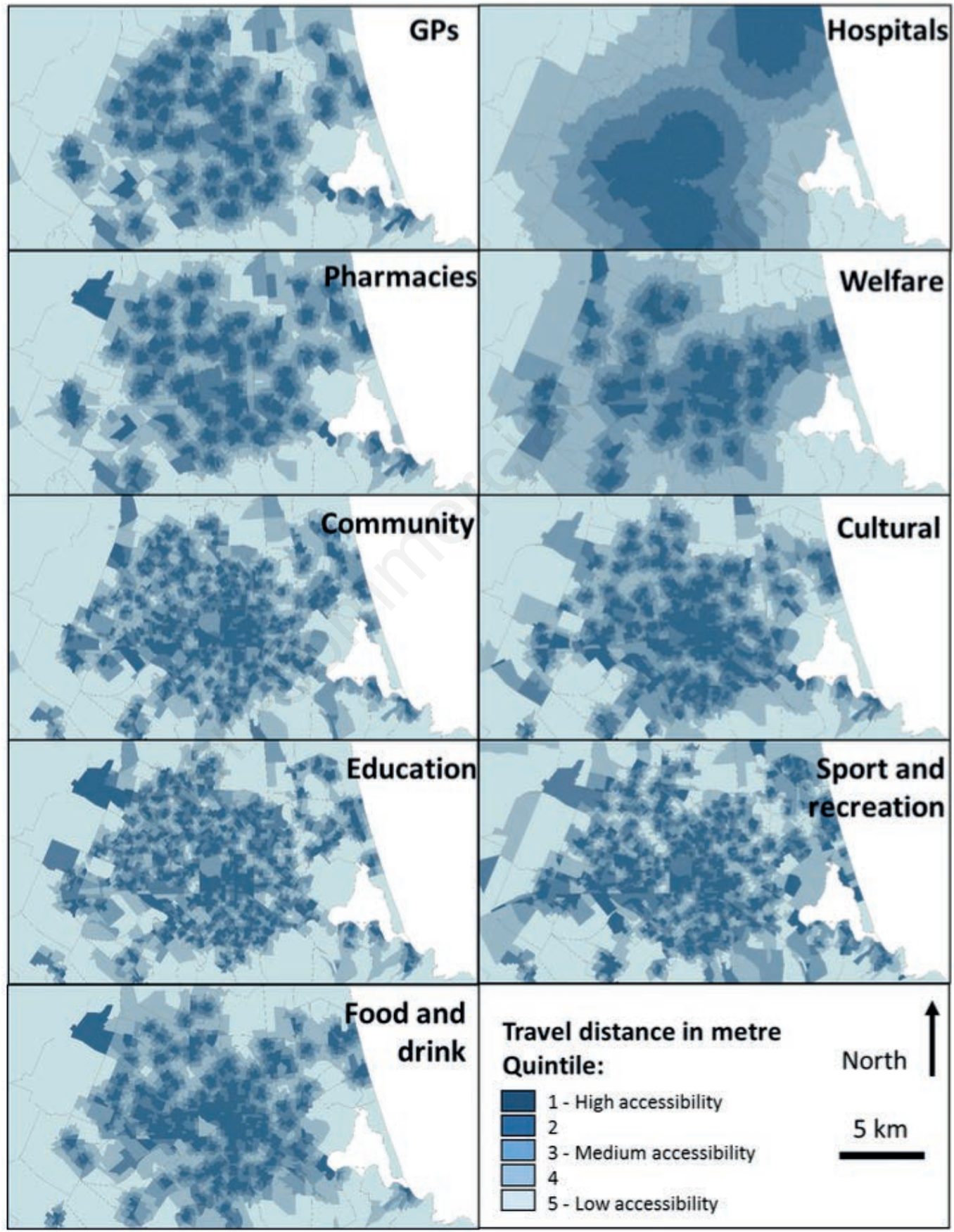

Figure 2. Travel distance maps from the place of residency (population weighted centroid by meshblocks) to the main facility, by service type. Zoom in Christchurch - Ötautabi city. 
of people living less than a 20 min walk away. It is the same pattern for the pharmacy coverage, with only $45.5 \%$ people living less than a 10 min walk from their nearest pharmacy, increasing to $85.3 \%$ for less than a 20 min walk. The percentages are also lower for welfare facilities with only $40.2 \%$ people $<10 \mathrm{~min}$ and $68.9 \%$ people $<20$ min away. However, the community, cultural, educational, sport, recreation, food and drink places are better distributed with more than $90 \%$ of the population $<20 \mathrm{~min}$ and $70 \%<10$ minute away (Table 3).
This scenario analysis is useful to better consider how well people can access different types of services. As socio-cultural places have been shown to play a key role in well-being, it is important to highlight the good coverage of these services all around the Christchurch area.

The level of accessibility to four categories of well-being service: health and welfare, community, cultural, sport and recreation; is shown (Figure 4). The two maps display the walking and driving scenarios separately. Results show that i) Christchurch city is well

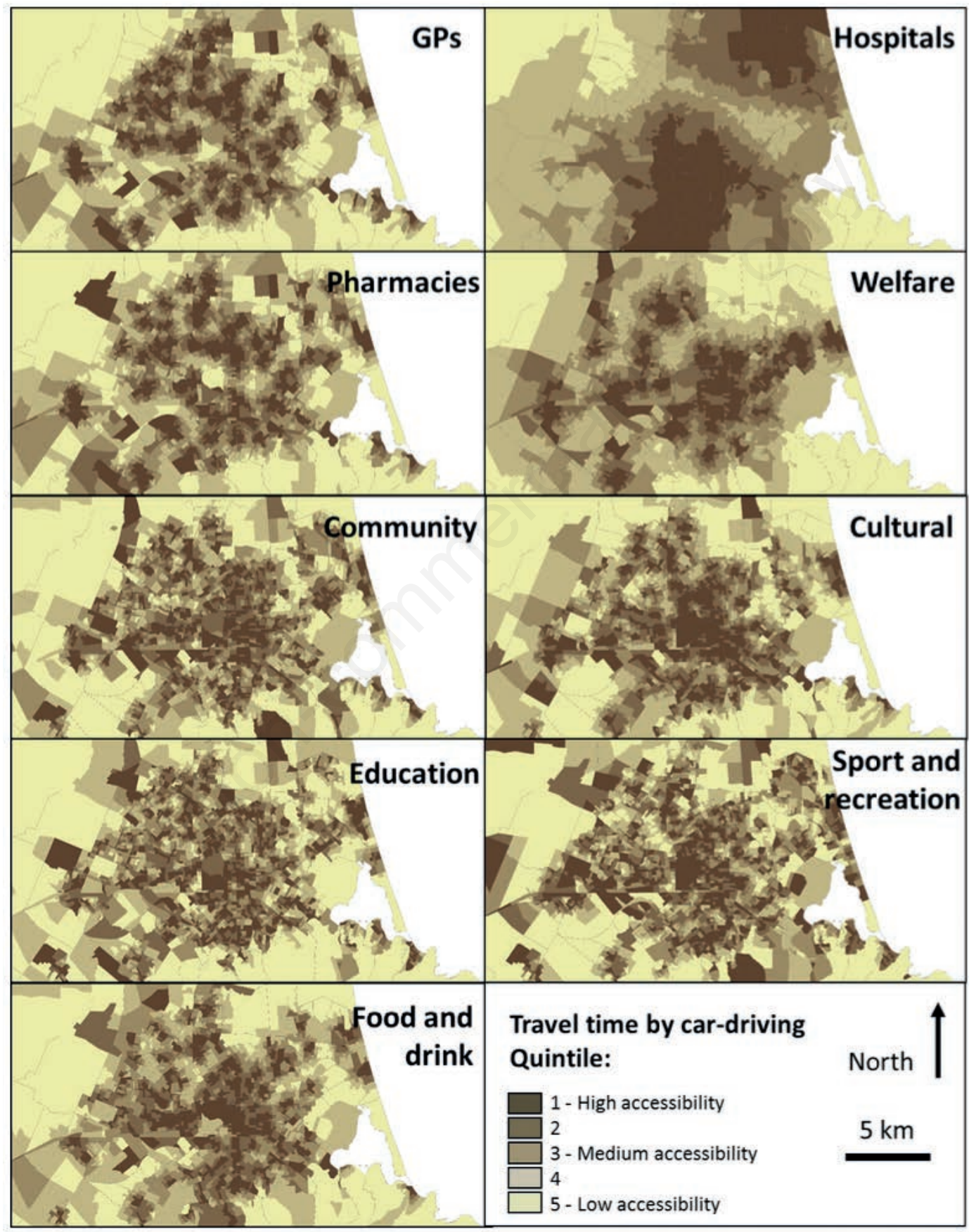

Figure 3. Travel driving-time maps from the place of residency (population weighted centroid by meshblocks) to the main facility, by service type. Zoom in Christchurch - Otautahi city. 
covered in terms of access to well-being services, ii) as expected, the further away from the centre, the less services are accessible, iii) even the small satellite urban areas (Rangiora, Kaiapoi, Woodend, West Melton, Rolleston, Lincoln, Lyttleton) have reasonable service accessibility. However the eastern suburbs are sparsely served (similar to the accessibility maps in Figures 2 and 3 ) with the socio-economic multiple deprived (Salmond et al. 1998; Exeter et al. 2017).

\section{A location-allocation model optimises inhabitants' accessibility}

\section{General Practitioners}

If we want to i) minimize the number of facilities and keep the same coverage (i.e. the same percentage of people that can reach the nearest GP in $<10$ min driving), only 18 of the 114 centres are technically allowed. This result shows that 18 centroids points can geographically cover the same number of living places than the 114 existing. But we can think about relocating some places to ii) maximize the attendance and so increase the current accessibility. With the same number of facilities (114), keeping 26 of the current places and relocating 88 in existing health and welfare facility places, would increase accessibility to $99.82 \%$ of people $(401,235)$ living within $10 \mathrm{~min}$ driving time. This scenario would increase the accessibility up to $68 \%$ and $90.2 \%$ of people to less than 10 - and 20 -min walking, respectively (i.e. $+11.4 \%$ and $+3.6 \%$ respectively). If we want to iii) maximize the coverage of GP facilities, we will need to add nine places (from existing health and welfare or community facilities) to have $100 \%$ of Christchurch inhabitants within 10 min driving time. This scenario would not change anything for the walking people. It is explained by the rurality of the nine new places, far from living places but easily accessible by car.

\section{Pharmacies}

If we want to i) minimize the number of facilities and keep the same coverage, only 16 of the 125 centres would remain. But if we relocate some places to ii) maximize the attendance and increase the current accessibility, with keeping 6 of the current places and relocate 119 in existing health and welfare places, this would increase accessibility to $99.82 \%$ of people $(401,235)$ in less than $10 \mathrm{~min}$ driving. This scenario would increase the accessibility up to $69.5 \%$ and to $90.4 \%$ of people living within a 10 and $20 \mathrm{~min}$ walk away respectively (i.e. $+24 \%$ and $+5.1 \%$ respectively). Finally, if we want to iii) maximize the coverage of pharmacy facilities, we will need to add 10 places (from existing health and welfare or community facilities) to have $100 \%$ of Christchurch inhabitants within 10 min driving. This scenario would allow an increase of accessibility up to $54.2 \%$ and up to $85.6 \%$ of people by walking less than 10 and 20 min respectively (i.e. $+8.7 \%$ and $+0.3 \%$ respectively).

\section{Welfare places}

If we want to i) minimize the number of facilities and keep the same coverage, only 14 of the 109 centres would remain. But if we

Table 3. Amount of people covered by current facilities.

\begin{tabular}{|c|c|c|c|c|c|c|}
\hline \multirow[t]{2}{*}{ Service category } & \multicolumn{3}{|c|}{ Walking distance } & \multicolumn{3}{|c|}{ Driving time } \\
\hline & $<10$ min & 10-20 min & $>20 \mathrm{~min}$ & $<5$ min & $5-10 \mathrm{~min}$ & $>10$ min \\
\hline \multirow[t]{2}{*}{ All health and welfare } & 316,296 & 54,981 & 30,681 & 389,181 & 12,054 & 723 \\
\hline & 78.7 & 13.7 & 7.6 & 96.8 & 3 & 0.2 \\
\hline \multirow[t]{2}{*}{ GPs } & 227,526 & 120,639 & 53,793 & 380,190 & 16,644 & 5,124 \\
\hline & 56.6 & 30 & 13.4 & 94.6 & 4.1 & 1.3 \\
\hline \multirow[t]{2}{*}{ Public hospitals } & 8,250 & 29,898 & 363,810 & 53,520 & 191,289 & 157,149 \\
\hline & 2.1 & 7.4 & 90.5 & 13.3 & 47.6 & 39.1 \\
\hline \multirow[t]{2}{*}{ Pharmacies } & 182,844 & 160,050 & 59,064 & 375,585 & 19,746 & 6,627 \\
\hline & 45.5 & 39.8 & 14.7 & 93.4 & 4.9 & 1.6 \\
\hline \multirow[t]{2}{*}{ Welfare } & 161,739 & 115,392 & 124,827 & 321,993 & 57,780 & 22,185 \\
\hline & 40.2 & 28.7 & 31.1 & 80.1 & 14.4 & 5.5 \\
\hline \multirow[t]{2}{*}{ Community } & 339,447 & 38,817 & 23,694 & 391,722 & 8,622 & 1,614 \\
\hline & 84.4 & 9.7 & 5.9 & 97.5 & 2.1 & 0.4 \\
\hline \multirow[t]{2}{*}{ Cultural } & 284,538 & 78,396 & 39,024 & 387,255 & 14,295 & 408 \\
\hline & 70.8 & 19.5 & 9.7 & 96.3 & 3.6 & 0.1 \\
\hline \multirow[t]{2}{*}{ Education } & 356934 & 25,731 & 19,293 & 396,525 & 5,433 & 0 \\
\hline & 88.8 & 6.4 & 4.8 & 98.6 & 1.4 & 0 \\
\hline \multirow[t]{2}{*}{ Sport and recreation } & 363,894 & 25,044 & 13,020 & 400,293 & 1,665 & 0 \\
\hline & 90.5 & 6.2 & 3.2 & 99.6 & 0.4 & 0 \\
\hline \multirow[t]{2}{*}{ Food and drink } & 276,171 & 86,466 & 39,321 & 384,207 & 15,738 & 2,013 \\
\hline & 68.7 & 21.5 & 9.8 & 95.6 & 3.9 & 0.5 \\
\hline \multirow[t]{2}{*}{ Green spaces } & 397,239 & 4719 & 0 & 401,958 & 0 & 0 \\
\hline & 98.8 & 1.2 & 0 & 100 & 0 & 0 \\
\hline \multirow[t]{2}{*}{ Blue spaces } & 326,025 & 70,689 & 5,244 & 392,655 & 9,303 & 0 \\
\hline & 81.1 & 17.6 & 1.3 & 97.7 & 2.3 & 0 \\
\hline
\end{tabular}

Non-italics = numbers of people; Italics $=$ expressed as percentage 
relocate some places to ii) maximize the attendance and increase the current accessibility, 19 of the current places would remain and 100 existing health and welfare facility places would be relocated, increase accessibility to $99.82 \%$ of people $(401,235)$. This scenario would increase the accessibility up to $66.5 \%$ and to $90.1 \%$ of people walking less than 10 and 20 min respectively (i.e. $+26.3 \%$ and $+21.2 \%$ respectively). Finally, if we want to iii) maximize the cov- erage of welfare facilities, we will need to add 14 places (from existing health and welfare or community facilities) to have $100 \%$ of Christchurch inhabitants within 10 min driving. This scenario would allow to increase the accessibility up to $43 \%$ and up to $73.8 \%$ of people walking less than 10 and 20 min respectively (i.e. $+2.8 \%$ and $+4.9 \%$ respectively).

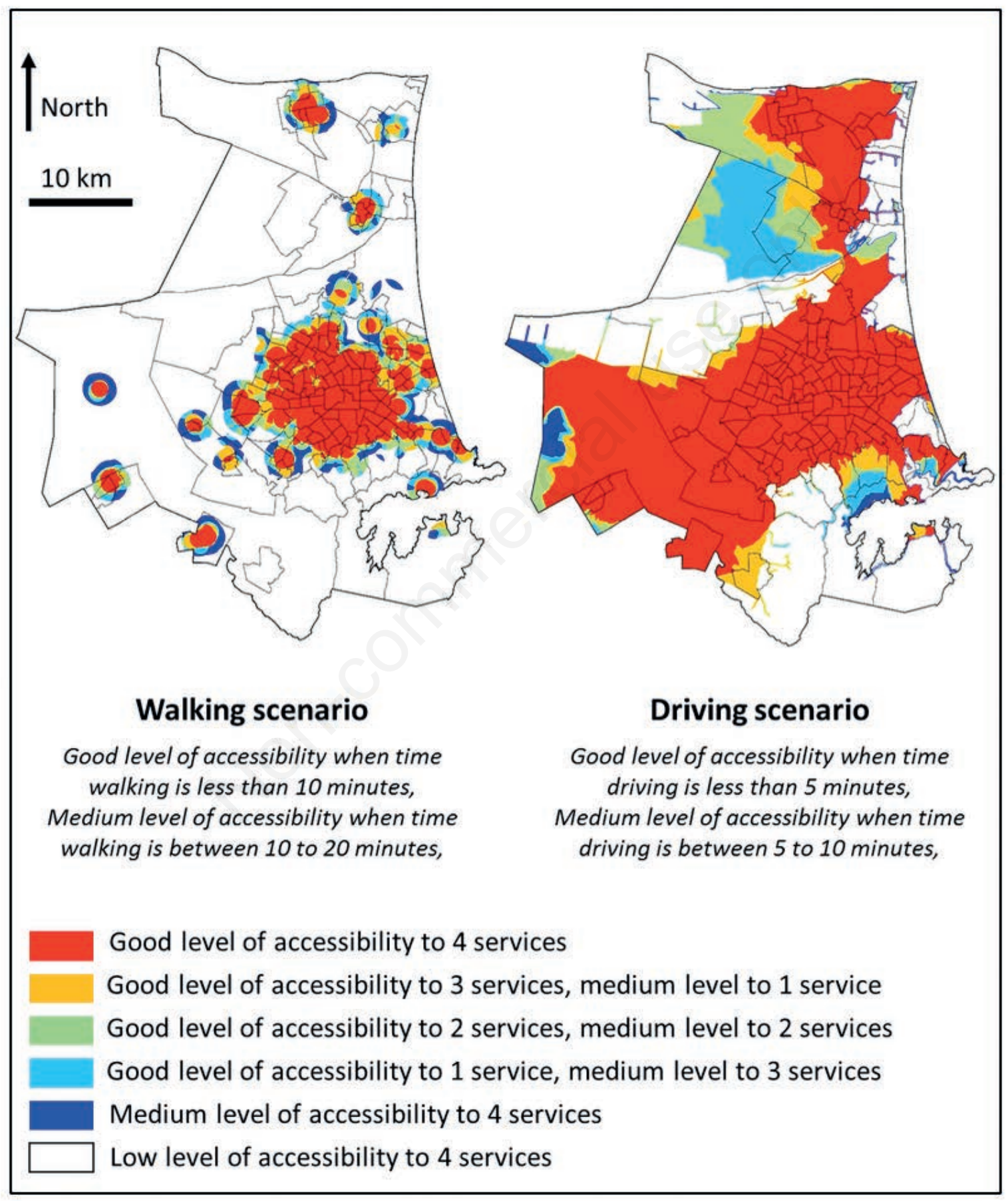

Figure 4. Level of accessibility to one to four well-being type of services (i.e. health and welfare, community, cultural, sport and recreation) within a walking and a driving scenario, in the Christchurch - Ötautabi catchment area. 


\section{Discussion}

\section{Study strengths and innovation}

The main strength and innovative element of the study rely on the wide range of different sort of data and services merge together to analyse and model accessibility and optimization in a dynamic medium size city. We spatially merged together and analysed 9 health and well-being service types provided by 6 different type of data sources, which represent 36,037 entities (4,791 facilities and 31,246 green and blue entities). National scale analysis (like Pearce et al., 2006; Wiki et al., 2018) cannot use the specific service database we used, such as Community Information Christchurch (CINCH) which covers only the Christchurch City Council area. Although it is a fundamental resource for evaluating accessibility to community services, it does not exist for all the main NZ cities, although they may collect or collate their own similar data. One of the main strengths of this study is also a weakness from another point of view, because of the non-reproducibility and comparability across the main cities of the country.

Using Christchurch as a study case represents another strength of this study. Although Christchurch is considered as a successful resilient city, its architecture and community are still in a rebuilding process. This already connected community before the earthquakes helped to adapt after disaster and explains the high resilience level of the community (Thornley et al., 2015). These accessibility analysis findings highlighted a very active community, as socio-cultural places were determined of very good coverage all around Christchurch and the whole catchment area.

\section{Limitations}

The accessibility analysis and scenario modelling have been computed by a very common way regarding the rich literature of this type of processing (Neutens, 2015). However, we chose to develop the scenario analysis for two different travel mode: walking and driving. Our results have highlighted different disparities according to these two transport modes. The Christchurch Eastern suburbs are for example sparsely served depending on the walking or driving scenario. This result is however consistent with other accessibility studies highlighted the less service coverage for more deprived suburbs (Guagliardo, 2004; Zhou and Kim, 2013; Shah et al., 2016).We note that the more or less complex GIS analysis method does not change these general trends. While car travel time seems to be wellestimated to local conditions (Beere, 2016), the walking speed used is based on the average passage by healthy young adults', and computed for a single walking speed. Several studies have shown that a walking speed can vary a lot depending on a wide range of parameters (age, height, weight, level of fitness, etc.). For example for people with LTCs like diabetes, obesity, or elderly people, the walking speed can vary from $6.5 \mathrm{~km} / \mathrm{h}$ for healthy adults to $3 \mathrm{~km} / \mathrm{h}$ for vulnerable ones (Camarri et al., 2006; Chetta et al., 2006; Adeniyi et al., 2009). In the case of pedestrian suburbs' design, like the in-rebuilding-process Christchurch city centre, it should then be useful to take into account different walking speed thresholds to cover a more diverse population. Another way of improvement of this study rely on taking into account more transport modes like cycling or scootering, or the use of public transport. As NZ cities are currently investigating a lot of new transport modes (e.g. shared electric scooters, autonomous vehicles) (Ministry of Transport - Te Manatu Waka, 2016) it should be interesting to conduct this type of accessibility analysis when they will be settle in the new central Christchurch city.

\section{Future work: strengthening the community process}

The accessibility and modelling findings can be used either for planning purposes, to improve welfare coverage for example, or for better connect people with their local communities. As it is already demonstrated that social connectedness improve mental health (Saeri et al., 2018), it looks interesting to develop a complete and searchable web-map tool merging the large online resource already available like CINCH (http://www.cinch.org.nz/), Active Canterbury (https://www.activecanterbury.org.nz/), Sport Canterbury (https://www.sporty.co.nz/sportcanterbury), or Canterbury Men's Centre (http://canmen.org.nz/). Many of the places registered in these websites are already merged in the $\mathrm{CINCH}$ database. This is a great example of a community database, that groups together community places, cultural, sport and recreation activities, etc. that is up to date and almost complete according to the Christchurch City Council (CCC) database management team. Merging together all the available community information in a searchable web-map tool represents a key product for a successful analysis and for a successful community life. Moreover, spatial database are often complex and difficult to access for stakeholders, that makes decision planning and urban development even more difficult (Schindler et al., 2018). Kingston (2007) has demonstrated by the use of a web-based mapping how citizens can improve services to local communities for a management purpose.

\section{Conclusions}

This study demonstrates the planning potentials for a community, of an accessibility analysis and a model location optimisation, using a wide range of health and well-being services, in a medium-size city. Firstly, the curation of the database demonstrated the substantial amount, both in terms of quantity and in diversity, of the well-being and community services' in Christchurch. This illustrates the unique and genuine NZ culture, valuing high the community and volunteering process, and explains the high resilience level of the community (Grant, 2017; Kenney, 2019). Secondly, using GIS accessibility analysis and model computation, the results highlighted the multiple activity centres of Christchurch and the small urban satellite areas around the outer urban footprint of the city. Primary health care services like GPs and pharmacies are evenly distributed across the Christchurch catchment area, while welfare facilities even with more than a hundred of different places are sparsely and unevenly spatially distributed. However, the positive results remain for the more easily accessible socio-cultural places as well as for green and blue spaces, both for walking and driving, indicating an even spread across the city. This can be considered a positive result as these place have demonstrated positive impacts on mental health and well-being for the whole population (Carrus et al., 2015; Dadvand et al., 2015; Thompson and Aspinall, 2011). Thirdly, the location optimisation model showed a reasonable level of equity for accessibility (in terms of the number of people covered in a reasonable travel time or distance). For example, scenarios showed the improvement of accessibility equity can be reached by making community places available for primary health care. The findings of this study therefore demonstrate not only the usefulness of a spatial web mapping tool in its own right, but also the importance of understanding the spatial distribution of community resources for planning purposes and their potential ameliorative impacts on health and well-being. 


\section{References}

Adeniyi AF, Uloko AE, Sani-Suleiman I, 2009. Exercise Capacity in Type 2 Diabetes Patients: A Preliminary Investigation. Afr. J Biomed Res 12:175-9.

Ala-Hulkko T, Kotavaara O, Alahuhta J, Helle P, Hjort J, 2016. Introducing accessibility analysis in mapping cultural ecosystem services. Ecol Indic 66:416-27. doi: 10.1016/j.ecolind.2016.02.013

Albino V, Berardi U, Dangelico RM, 2015. Smart Cities: Definitions, Dimensions, Performance, and Initiatives. J Urban Technol 22:3-21. doi: 10.1080/10630732.2014.942092

Bagheri N, Benwell GL, Holt A, 2005. Measuring spatial accessibility to primary health care.

Bagnall AM, South J, Di Martino S, Southby K, Pilkington G, Mitchell, B., Pennington, A., Corcoran, R., 2018. Places, spaces, people and wellbeing: full review. School of Health and Community Studies, Leeds Beckett University, Leeds, UK.

Beere P, 2016. Creating a Road Network Analysis Layer with Travel Time Estimates using Opensource Data. GeoHealth Laboratory University of Canterbury, Christchurch, New Zealand.

Beheshtifar S, Alimoahmmadi A, 2015. A multiobjective optimization approach for location-allocation of clinics. Int Trans Oper Res 22:313-28. doi: 10.1111/itor.12088

Camarri B, Eastwood PR, Cecins NM, Thompson PJ, Jenkins S, 2006. Six-minute walk distance in healthy subjects aged 55-75 years. Respir Med 100:658-65. doi: 10.1016/j.rmed. 2005.08.003

Carrus G, Scopelliti, M., Lafortezza, R., Colangelo, G., Ferrini, F., Salbitano, F., Agrimi, M., Portoghesi, L., Semenzato, P., Sanesi, G., 2015. Go greener, feel better? The positive effects of biodiversity on the well-being of individuals visiting urban and peri-urban green areas. Landsc Urban Plan 134:221-8. doi: 10.1016/j.landurbplan.2014.10.022

Cetin M, 2015. Using GIS analysis to assess urban green space in terms of accessibility: case study in Kutahya. Int J Sustain Dev World Ecol 22:420-4. doi: 10.1080/13504509.2015.1061066

Chen IH, Kuo KN, Andriacchi TP, 1997. The influence of walking speed on mechanical joint power during gait. Gait Posture 6:171-6. doi: 10.1016/S0966-6362(97)00009-X

Chetta A, Zanini A, Pisi G, Aiello M, Tzani P, Neri M, Olivieri D, 2006. Reference values for the 6-min walk test in healthy subjects 20-50 years old. Respir Med 100:1573-8. doi: 10.1016/j.rmed.2006.01.001

Costanza R, d'Arge R, de Groot R, Farber S, Grasso M, Hannon B, Limburg K, Naeem S, O’Neill RV, Paruelo J, Raskin RG, Sutton P, van den Belt M, 1997. The value of the world's ecosystem services and natural capital. Nature 387:253-60. doi: $10.1038 / 387253 \mathrm{a} 0$

Costanza R, Fisher B, Ali S, Beer C, Bond L, Boumans R, Danigelis NL, Dickinson J, Elliott C, et al, 2007. Quality of life: An approach integrating opportunities, human needs, and subjective well-being. Ecol Econ 61:267-76. doi: 10.1016/j.ecolecon.2006.02.023

Cram F, McCreanor T, Tuhiwai Smith L, Nairn R, Johnstone W, 2006. Kaupapa Māori Research and Pākehā Social Science: Epistemological Tensions in a Study of Māori Health. Hülili: Multidisciplinary Research on Hawaiian Well-Being 3:41-68.

Dadvand P, Nieuwenhuijsen MJ, Esnaola M, Forns J, Basagaña X,
Alvarez-Pedrerol M, Rivas I, et al., 2015. Green spaces and cognitive development in primary schoolchildren. Proc. Natl Acad Sci 112:7937-42. doi: 10.1073/pnas.1503402112

Ekkel ED, de Vries S, 2017. Nearby green space and human health: Evaluating accessibility metrics. Landsc. Urban Plan. 157:214-20. doi: 10.1016/j.landurbplan.2016.06.008

Exeter DJ, Zhao J, Crengle S, Lee A, Browne M, 2017. The New Zealand Indices of Multiple Deprivation (IMD): A new suite of indicators for social and health research in Aotearoa, New Zealand. PLOS ONE 12:e0181260. doi: 10.1371/journal.pone. 0181260

Finlay J, Franke T, McKay H, Sims-Gould J, 2015. Therapeutic landscapes and wellbeing in later life: Impacts of blue and green spaces for older adults. Health Place 34:97-106. doi: 10.1016/j.healthplace.2015.05.001

Gascon M, Triguero-Mas M, Martínez D, Dadvand P, Forns J, Plasència A, Nieuwenhuijsen M, et al., 2015. Mental Health Benefits of Long-Term Exposure to Residential Green and Blue Spaces: A Systematic Review. Int. J. Environ. Res. Public. Health 12:4354-79. doi: 10.3390/ijerph120404354

Grant S, 2017. Social enterprise in New Zealand: an overview. Soc Enterp J 13:410-26. doi: 10.1108/SEJ-09-2017-0046

Guagliardo MF, 2004. Spatial accessibility of primary care: concepts, methods and challenges. Int J Health Geogr 3:3. doi: 10.1186/1476-072X-3-3

Guerry AD, Polasky S, Lubchenco J, Chaplin-Kramer R, Daily GC, Griffin, R., Ruckelshaus, M., et al, 2015. Natural capital and ecosystem services informing decisions: From promise to practice. Proc. Natl. Acad. Sci. 112, 7348-55. doi: 10.1073/ pnas. 1503751112

Harmthworth GR, Awatere S, 2013. Indigenous Māori knowledge and perspectives of ecosystems. In: New Zealand - Conditions and Trends. Manaaki Whenua Press, Lincoln, New Zealand, pp. 274-286.

Helliwell JF, Putnam RD, 2004. The social context of well-being. Philos Trans R Soc B Biol Sci 359:1435-46. doi: 10.1098/rstb.2004.1522

Hogg D, Kingham S, Wilson TM, Ardagh M, 2016. The effects of relocation and level of affectedness on mood and anxiety symptom treatments after the 2011 Christchurch earthquake. Soc. Sci. Med. 1982 152, 18-26. https://doi.org/ 10.1016/j. socscimed.2016.01.025

Kenney C, 2019. Ahi Kā Roa, Ahi Kā Ora Ōtautahi: Māori, Recovery Trajectories and Resilience in Canterbury, New Zealand, in: James, H. (Ed.), Population, Development, and the Environment: Challenges to Achieving the Sustainable Development Goals in the Asia Pacific. Springer Singapore, Singapore, pp. 375-394. doi: 10.1007/978-981-13-2101-6_22

Kingham S, Dioniso R, Newman P, 2015. The right tools at the right time: Encouraging community involvement in the postdisaster reconstruction of Christchurch, New Zealand. Presented at the IGU Urban Commission Annual Conference, 9th-16th August 2015, University College Dublin, Dublin, Ireland.

Kingston R, 2007. Public Participation in Local Policy Decisionmaking: The Role of Web-based Mapping. Cartogr J 44:138144. doi: $10.1179 / 000870407 \mathrm{X} 213459$

Langford M, Higgs G, 2006. Measuring Potential Access to Primary Healthcare Services: The Influence of Alternative Spatial Representations of Population. Prof Geogr 58:294 306. doi: 10.1111/j.1467-9272.2006.00569.x 
Marans RW, 2015. Quality of urban life \& environmental sustainability studies: Future linkage opportunities. Habitat Int., Measuring the Prosperity of Cities 45:47-52. doi: 10.1016/j.habitatint.2014.06.019

Marek L, Campbell M, Bui L, 2017. Shaking for innovation: The (re)building of a (smart) city in a post disaster environment. Cities 63:41-50. doi: 10.1016/j.cities.2016.12.013

Masser I, 2001. Managing our urban future: the role of remote sensing and geographic information systems. Habitat Int. 25:503-12. doi: 10.1016/S0197-3975(01)00021-2

McGrail MR, Humphreys JS, 2014. Measuring spatial accessibility to primary health care services: Utilising dynamic catchment sizes. Appl Geogr 54:182-8. doi: 10.1016/j.apgeog. 2014.08.005

Meng YL, Malczewski J, 2015. A GIS-based multicriteria decision making approach for evaluating accessibility to public parks in Calgary, Alberta. Hum Geogr - J Stud Res Hum Geogr 9:29_ 41.

Ministry of Transport - Te Manatu Waka, 2016. Transport Outlook: Future state. A starting discussion on the future of transport in New Zealand. Ministry of Transport New Zealand, Wellington.

Nahapiet J, Ghoshal S, 1998. Social Capital, Intellectual Capital, and the Organizational Advantage. Acad Manage Rev 23, 242 66. doi: $10.2307 / 259373$

Neutens T, 2015. Accessibility, equity and health care: review and research directions for transport geographers. J Transp Geogr 43:14-27. doi: 10.1016/j.jtrangeo.2014.12.006

Orchiston C, Higham JES, 2016. Knowledge management and tourism recovery (de)marketing: the Christchurch earthquakes 2010-2011. Curr Issues Tour 19:64-84. doi:10.1080/ 13683500.2014 .990424

Pearce J, Witten K, Bartie P, 2006. Neighbourhoods and health: a GIS approach to measuring community resource accessibility. J. Epidemiol. Community Health 60:389-95. doi: 10.1136/jech.2005.043281

Polo, G., Acosta, C.M., Ferreira, F., Dias, R.A., 2015. LocationAllocation and Accessibility Models for Improving the Spatial Planning of Public Health Services. Plos One 10:e0119190. doi: 10.1371/journal.pone.0119190

Saeri, A.K., Cruwys, T., Barlow, F.K., Stronge, S., Sibley, C.G., 2018. Social connectedness improves public mental health: Investigating bidirectional relationships in the New Zealand attitudes and values survey. Aust N Z J Psychiatry 52:365-74. doi: $10.1177 / 0004867417723990$

Salmond C, Crampton P, Sutton F, 1998. NZDep91: A New Zealand index of deprivation. Aust N Z J Public Health 22:835-37. doi: 10.1111/j.1467-842X.1998.tb01505.x

Sargisson, L., Sargent, L.T., Sargent, L.T., 2017. Living in Utopia : New Zealand's Intentional Communities. Routledge doi: 10.4324/9781315250342

Schindler M, Dionisio R, Kingham S, 2018. A multi-level perspective on a spatial data ecosystem: needs and challenges among urban planning stakeholders in New Zealand. International Journal of Spatial Data Infrastructures Research 13:223-52. doi: 10.2902/1725-0463.2018.13.art15
Shah TI, Bell S, Wilson K, 2016. Spatial Accessibility to Health Care Services: Identifying under-Serviced Neighbourhoods in Canadian Urban Areas. PLOS ONE 11:e0168208. doi: 10.1371/journal.pone.0168208

Smoyer $\square$ Tomic KE, Hewko JN, Hodgson MJ, 2004. Spatial accessibility and equity of playgrounds in Edmonton, Canada. Can Geogr Géographe Can 48:287-302. doi: 10.1111/j.00083658.2004.00061.x

Terrier P, Reynard F, 2015. Effect of age on the variability and stability of gait: A cross-sectional treadmill study in healthy individuals between 20 and 69 years of age. Gait Posture 41:170 4. doi: 10.1016/j.gaitpost.2014.09.024

Thompson CW, Aspinall PA, 2011. Natural Environments and their Impact on Activity, Health, and Quality of Life. Appl. Psychol. Health Well-Being 3230-60. doi: 10.1111/j.17580854.2011.01053.x

Thornley L, Ball J, Signal L, Aho KLT, Rawson E, 2015. Building community resilience: learning from the Canterbury earthquakes. Kōtuitui N Z J Soc Sci Online 10:23-35. doi: 10.1080/1177083X.2014.934846

Tsou KW, Hung YT, Chang YL, 2005. An accessibility-based integrated measure of relative spatial equity in urban public facilities. Cities 22:424-35. doi: 10.1016/j.cities.2005.07.004

Vemuri AW, Costanza R, 2006. The role of human, social, built, and natural capital in explaining life satisfaction at the country level: Toward a National Well-Being Index (NWI). Ecol Econ 58:119-33. doi: 10.1016/j.ecolecon.2005.02.008

Wiki J, Kingham S, Campbell M, 2018. Accessibility to food retailers and socio-economic deprivation in urban New Zealand. N Z Geogr doi: 10.1111/nzg.12201

Wiseman J, Brasher K, 2008. Community wellbeing in an unwell world: trends, challenges, and possibilities. J. Public Health Policy 29:353-66. doi 10.1057/jphp.2008.16

Wood A, Noy I, Parker M, 2016. The Canterbury rebuild five years on from the Christchurch earthquake. Reserve Bank N Z Bull 79:1-16.

Wridt P, 2010. A Qualitative GIS Approach to Mapping Urban Neighborhoods with Children to Promote Physical Activity and Child-Friendly Community Planning. Environ Plan B Plan Des 37:129-47. doi: 10.1068/b35002

Yeo IA, Yoon SH, Yee JJ, 2013. Development of an Environment and energy Geographical Information System (E-GIS) construction model to support environmentally friendly urban planning. Appl. Energy 104:723-39. doi: 10.1016/j.apenergy.2012.11.053

Zhang W, Cao K, Liu S, Huang B, 2016. A multi-objective optimization approach for health-care facility location-allocation problems in highly developed cities such as Hong Kong. Comput Environ Urban Syst 59:220-30. doi: 10.1016/j.compenvurbsys.2016.07.001

Zhou X, Kim J, 2013. Social disparities in tree canopy and park accessibility: A case study of six cities in Illinois using GIS and remote sensing. Urban For. Urban Green. 12:88-97. doi: 10.1016/j.ufug.2012.11.004 